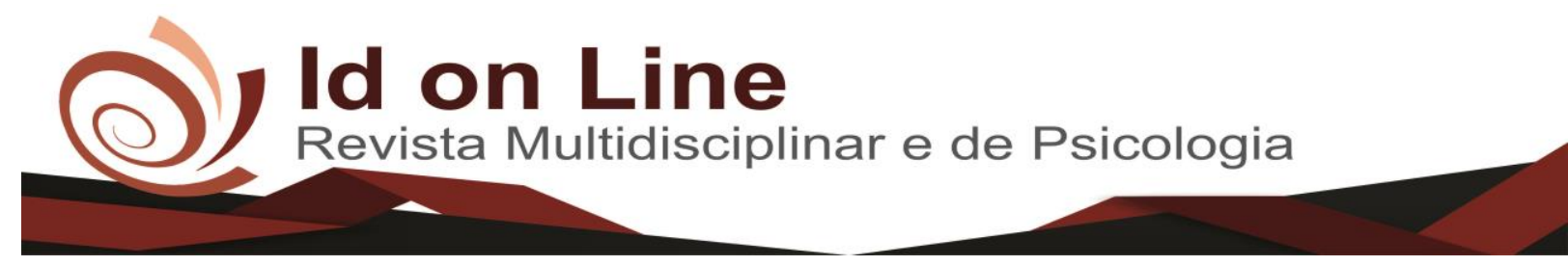

Artigo

\title{
A Gestão do Fluxo de Caixa no Âmbito Empresarial
}

\author{
Jair Bruno Pereira de Sousa ${ }^{1}$; Tays Cardoso Dias ${ }^{2}$
}

\begin{abstract}
Resumo: Este trabalho constitui na apresentação da demonstração do fluxo de caixa como ferramenta de auxílio no ambiente empresarial. Tendo em vista que tal demonstração em sua estrutura de elaboração constitui as entradas e saídas do dinheiro, ou seja, as origens e aplicações de recursos. A DFC é uma ferramenta indispensável nos dias atuais, pois com ela o gestor pode acompanhar de forma simples e clara as mutações ocorridas em determinado período e a partir dessa informação obter uma decisão centrada. A DFC possui duas formas de elaboração, o método direto e o método indireto, tendo como a mais utilizada no Brasil o método direto. Além de possuir duas formas de elaboração a DFC também é dividida em atividades operacionais, de financiamento e de investimento, facilitando ao usuário final uma ampla visão do financeiro-econômico da empresa. As entidades nos dias atuais não necessitam apenas do gerenciamento tradicional, precisa-se organizar e controlar os recursos financeiros, pois é através desses recursos que a organização projeta fluxos de caixa futuro e cumpri com seus deveres com os fornecedores. Por fim, concluímos com esse trabalho que o uso contínuo da DFC auxilia nos resultados para sobrevivência do caixa da empresa e na tomada de decisão, e quando usada definitivamente contribui para o crescimento e melhor posicionamento no mercado.
\end{abstract}

Palavras chaves: Fluxo de caixa. Empresarial. Gerenciamento.

\section{Corporate Cash Flow Management}

\begin{abstract}
This paper presents the cash flow statement as an aid to the business environment. Considering that such a demonstration in its elaboration structure constitutes the inflows and outflows of money, that is, the origins and applications of resources. The DFC is an indispensable tool in the present day, because with it the manager can follow in a simple and clear way the mutations occurred in a certain period and from this information to obtain a focused decision. The DFC has two forms of elaboration, the direct method and the indirect method, having as the most used in Brazil the direct method. In addition to having two forms of elaboration, the DFC is also divided into operational, financing and investment activities, providing the end user with a broad financial-economic view of the company. Today's entities do not only need traditional management, they need to organize and control financial resources, because it is through these resources that the organization projects future cash flows and fulfills its duties with suppliers. Finally, we conclude from this work that the continued use of DFC helps in the results for company cash survival and decision making, and when used definitely contributes to growth and better positioning in the market.
\end{abstract}

Keywords: Cash flow. Business. Management.

\footnotetext{
${ }^{1}$ Graduando do curso de Ciências Contábeis do Centro Universitário Doutor Leão Sampaio. E-mail: brunojair@hotmail.com ${ }^{2}$ Professora Orientadora Docente do Centro Universitário Doutor Leão Sampaio, especialista em Contabilidade tributária pela Faculdade de Juazeiro do Norte - FJN. E-mail: taysdias@ leaosampaio.edu.br

873 Id on Line Rev. Mult. Psic. V.13, N. 43, p. 873-887, 2019 - ISSN 1981-1179

Edição eletrônica em http://idonline.emnuvens.com.br/id
} 


\section{Introdução}

O fluxo de caixa é um relatório contábil que evidência as entradas e saídas de dinheiro das empresas. Com esse relatório, evidencia-se as origens e aplicações de todo o dinheiro que, de forma direta ou indireta, afetam o disponível da empresa.

A gestão dos recursos financeiros é essencial para a tomada de decisão, principalmente as de âmbito financeiro, por ser uma demonstração que envolve apenas o disponível das entidades muitas acabam não utilizando estas informações como auxilio. Diante deste fato buscou-se evidenciar a utilização da DFC no âmbito empresarial.

O objetivo deste trabalho constitui em demonstrar como a DFC auxilia na tomada de decisão, para isso foi necessário apresentar a estrutura da demonstração, os tipos de elaboração e apresentar as informações contidas nesse demonstrativo.

A contabilidade vem se tornando uma ferramenta indispensável para os gestores, devido as informações obtidas de forma clara e específica, porém, sem o devido planejamento é difícil controlar todas essas informações e com isso as entidades acabam tendo dificuldades com a falta de recursos financeiros e consequentemente tornando-se insolventes. Nesse sentido, a DFC busca evidenciar as mudanças que ocorrem no disponível, ou seja, nas entradas e saídas de recursos financeiros, dando assim maior suporte e transparência nos resultados apurados.

Este trabalho foi desenvolvido por meio de uma abordagem qualitativa de cunho bibliográfico em que utilizou-se de obras de autores da área que foram aplicadas para dar suporte teórico a pesquisa.

\section{Demonstração do Fluxo de Caixa}

\section{Conceito}

A Demonstração do Fluxo de Caixa (DFC) é um relatório contábil que visa evidenciar as entradas e saídas do caixa das entidades, para com isso facilitar a tomada de decisão em determinadas situações em que necessita de informação em tempo hábil. Segundo Marion (2002, p. 54) "DFC evidencia as modificações ocorridas no saldo de disponibilidade (caixa e equivalente de caixa) da companhia em determinado período".

As entradas e saídas, que ocorrem diariamente no caixa das entidades, devem ser registrados no momento de seu acontecimento, dando assim eficiência na elaboração dessa 
demonstração.

Segundo a NBC TG 03 que trata sobre a DFC, conceitua que fluxos de caixa são as entradas e saídas de caixa e equivalentes de caixa. Já a Lei 6.404/76 afirma que o fluxo de caixa são as alterações ocorridas, durante o exercício, no saldo de caixa e equivalentes de caixa.

(MARION, 2005) afirma que caixa compreende o numerário em espécie e depósitos bancários disponíveis. Podendo ser utilizado de forma imediata pela entidade, quando necessário. Caixa, é o valor real que a entidade pode utilizar sem depender de terceiros.

Equivalente de caixa, segundo Iudícibus, (2010, p. 117) "São aplicações financeiras de curto prazo, de alta liquidez, que são prontamente conversíveis em montante de caixa". Completando, a NBC TG 03 afirma que "Para que um investimento seja qualificado como equivalente de caixa, ele precisa ter conversibilidade imediata em montante conhecido de caixa e estar sujeito a um insignificante risco de mudança de valor”.

\section{Obrigatoriedade}

A DFC no Brasil, diferente do EUA, não é uma demonstração utilizada de forma cotidiana, pois os responsáveis por sua elaboração julgam desnecessário a utilização dessa ferramenta no auxilio empresarial.

Como já foi dito anteriormente, a DFC engloba as entradas e saídas da entidade, dando importância a esse fato, um dos motivos da sua inutilidade é a cultura implantada no cenário empresarial. Na qual os gestores não revelam de forma clara a origem e uso do dinheiro, outro fato é a sonegação por parte do empresário, que se beneficiam com "caixa 2" ou utiliza-se dos recursos financeiros da entidade para uso pessoal (infligindo o princípio da entidade) impossibilitando a confiabilidade nas informações.

Por ser uma demonstração importante, torna-se obrigatória para algumas entidades. No Brasil, com alteração da Lei $n^{\circ} 6.404 / 76$ pela Lei $n^{\circ} 11.638 / 07$ que originou a Demonstração do Fluxo de Caixa, instituiu a obrigatoriedade para as companhias de capital aberto e capital fechado que na data do fechamento do Balanço o seu PL seja superior a 2 milhões de reais.

Substituindo a Demonstrações das Origens e Aplicações de Recursos (DOAR), na qual evidenciava as origens dos recursos e onde estão sendo aplicados, a DFC apresenta informações financeiras, ou seja, qual a importância em dinheiro entrou e saiu do caixa que 
na outra demonstração não era abordada de forma clara.

De acordo com a Lei $n^{\circ} 11.638 / 07$, as empresas que fecharem seu balanço ao final do exercício, com valor abaixo de 2 milhões de reais não serão obrigadas a elaborar a DFC.

Logo, as empresas tributadas no regime Simples Nacional, Empresa de Pequeno Porte e Microempreendedor Individual (MEI) não fazem parte desse critério.

Entretanto, fazer o Fluxo de Caixa beneficia tanto o administrador quanto a entidade, pois é a partir desta demonstração que será projetado fluxos futuros dando suporte ao gerenciamento. Marion (2005, p. 119) afirma que "Por outro lado, sem fluxo de caixa fica quase impossível projetar, planejar financeiramente".

Segundo Azevedo (2013, p. 93)

\begin{abstract}
"Quando essa demonstração é constituída a partir das informações divulgadas nas demonstrações contábeis, o usuário estará diante de um poderoso instrumento para medir a capacidade de solvência da empresa, bem como sua necessidade de financiamento a médio e longo prazo, à medida que se pode visualizar com precisão a capacidade de geração de caixa oriunda das suas próprias operações”.
\end{abstract}

Em conjunto com as demais demonstrações, em especifico a Demonstração do Resultado do Exercício (DRE) e o Balanço Patrimonial, o gestor terá subsídios necessários para o gerenciamento financeiro da entidade, visto que a junção dessas demonstrações lhe dará o mínimo de informações sobre o Patrimônio, situação Financeira e econômica da empresa.

\title{
Estrutura da DFC
}

\section{Métodos de elaboração}

A DFC como já mencionado, é dividida em método direto e indireto, contendo no corpo da sua estrutura as atividades operacionais, de investimento e financiamentos. Para elaborar a DFC deve-se observar em qual atividade principal a empresa está enquadrada. O dispositivo legal responsável por normatizar essa demonstração é o CPC 03 - Demonstração do Fluxo de Caixa, que determina a estrutura e sua composição.

As empresas com base no regime de competência, reconhecendo receitas (quando houver) e despesas (mesmo não pagas), usam a forma indireta para elaborar a DFC. Dessa forma, o Lucro Líquido apurado na DRE não evidencia o disponível, logo é necessário elaborar a DFC transformando essas informações no regime de caixa. 
As entidades devem analisar as principais atividades geradoras de receita e outras atividades que não são de investimento e tampouco de financiamento. Já em investimento, é tudo referente a aquisição e à venda de ativos de longo prazo, e de outros investimentos não incluídos nos equivalentes de caixa. Em financiamento resultam em mudanças no tamanho e na composição do capital próprio, e no capital de terceiros.

O planejamento das empresas é necessário para o gerenciamento como também nas situações em que esteja ocasionando prejuízos, sendo assim, esta demonstração ajuda na organização e crescimento da entidade. Com análise das informações financeiras, os gestores terão base para planejar metas mantendo a operacionalidade da companhia.

Para obter resultados nas demonstrações do fluxo de caixa é importante a análise, e verificação dos dados contidos na demonstração. Contudo, o empresário não deve basearse apenas nos dados gerados pela DFC pois a mesma não é uma demonstração totalmente completa.

Para Iudícibus e Marion (2011, p. 113) “A DFC vem esclarecer situações controvertidas na empresa". Como por exemplo, quando na DRE apura um lucro considerável e o caixa consta um valor inferior ao esperado.

A saúde financeira da entidade, exige um constante acompanhamento na qualidade das informações obtidas, para isso a gestão financeira deve trabalhar de forma clara no gerenciamento destes relatórios, utilizando-se das técnicas e métodos corretos para chegar aos resultados.

\section{Método direto}

Abordado anteriormente, a DFC é dividida de forma direta e indireta. A forma direta está ligada às vendas da entidade, começa-se a elaborar a demonstração a partir dos recebimentos de vendas e despesas obtidas,

A DFC, sendo elaborada de forma direta deve-se observar as classes de receita e despesa bruta, originadas da atividade operacional da entidade e subtraindo da natureza contábil - clientes e fornecedores, por exemplo. Este método, inicialmente começa com entradas e saídas que movimentarão o caixa e seu equivalente.

Contextualizando Braga (2012, p. 83). “Apresentação do método direto é de fácil compreensão mesmo por aqueles que têm pouco ou nenhum treinamento em contabilidade financeira". Por sua vez, Ribeiro (2002, p. 304) afirma que “A ideia desse método é bastante 
simples de ser entendido pelo usuário, pois as movimentações de dinheiro seguem uma ordem direta, como se faz com a administração do caixa pessoal”.

O método de direto, para Marion (2004, p. 120) "Destaca-se as entradas e saídas de dinheiro, informando a origem (fonte) e o uso (aplicação) ". Esse método de elaboração da DFC é claro e de fácil entendimento ao usuário da contabilidade, pois retrata de forma compreensiva as mutações ocorridas em determinada conta.

Apesar de ser um método bem elaborado, sua vantagem é destacar as contas que geram movimento e classifica-las nas entradas e saídas de acordo com os critérios técnicos e não fiscais, fornecendo informações diárias sobre o caixa.

A seguir um modelo da DFC elaborada pelo método direto.

\begin{tabular}{|c|}
\hline FLUXO DE CAIXA PELO MÉTODO DIRETO/ ANO X1 \\
\hline $\begin{array}{l}\text { Das atividades Operacionais } \\
\text { (+) Recebimento de Clientes e outros (-) } \\
\text { Pagamentos a Fornecedores } \\
\text { (-) Pagamento a Funcionários (- } \\
\text { ) Recolhimento ao Governo } \\
\text { (-) Pagamentos a credores diversos }\end{array}$ \\
\hline (=) Disponibilidades geradas pelas atividades operacionais \\
\hline $\begin{array}{l}\text { Das atividades de Investimentos } \\
\text { (+) Recebimento de venda de imobilizados (-) } \\
\text { Aquisição de Ativo Permanente } \\
\text { (+) Recebimento de Dividendos }\end{array}$ \\
\hline (=) Disponibilidades geradas pelas atividades de investimentos \\
\hline $\begin{array}{l}\text { Das atividades de Financiamentos } \\
\text { (+) Novos Empréstimos } \\
\text { (-) Amortização de Empréstimos } \\
\text { (+) Emissão de Debêntures } \\
\text { (+) Integralização de Capital } \\
\text { (-) Pagamentos de Dividendos }\end{array}$ \\
\hline (=) Disponibilidades geradas pelas atividades de Financiamentos \\
\hline AUMENTO/DIMINUIÇÃO NAS DISPONIBILIDADES \\
\hline DISPONIBILIDADES no início do período \\
\hline DISPONIBILIDADES no final do período \\
\hline
\end{tabular}

Fonte: Marion, (2004, p. 72) Tabela adaptada. 


\section{Método indireto}

Já no método indireto como citado, parte do lucro líquido da empresa com exceção das despesas e receitas que não influenciam no disponível, e são inclusas as receitas obtidas de forma não-operacional, por não está diretamente ligado ao caixa, essa demonstração se torna incompleta. De acordo com o NBC TG 1000 a DFC de forma indireta é elaborada com as "transações que não envolvem caixa".

O método no entanto, não é considerado perfeito por não lidar diretamente com o caixa e seus equivalentes, pois necessita-se converter as informações da DRE e o Balanço Patrimonial, elaboradas no regime de competência para o regime de caixa, processo que demanda tempo, principalmente quando feito de um exercício fiscal distante.

Franco $(1996$, p. 7 - 8), salientam vantagens e desvantagens que a DFC no modo indireto.

"Vantagens do Método Indireto

a) Apresenta baixo custo. Basta utilizar dois balanços patrimoniais (o do início e do final do período), a demonstração de resultados e algumas informações adicionais obtidas na contabilidade.

b) Concilia o lucro contábil com o fluxo de caixa operacional líquido, mostrando como se compõe a diferença.

Desvantagens do método indireto

a) O tempo necessário para gerar as informações pelo regime de competência e só depois convertê-las para regime de caixa. Se isso for feito uma vez por ano, por exemplo, podemos ter surpresas desagradáveis e tardiamente.

b) Se há interferência da legislação fiscal na contabilidade oficial, e geralmente há, o método indireto irá eliminar somente parte dessas distorções."

A seguir um modelo da DFC elaborada pelo método indireto.

\section{FLUXO DE CAIXA PELO MÉTODO INDIRETO / ANO X1}

\section{Entradas e Saídas de Caixa}

Fluxo de Caixa das Atividades Operacionais:

Lucro líquido

Depreciação e amortização (+) Provisão

para devedores duvidosos $(+)$

Aumento/diminuição em fornecedores (+/-) Aumento/diminuição em

contas a pagar (+/-) Aumento/diminuição em contas a receber (+/-) 


\begin{tabular}{|l|}
\hline Aumento/diminuição em estoques (+/-) \\
\hline Caixa líquido das atividades operacionais (+/-) \\
\hline Fluxo de Caixa das Atividades de Investimento: \\
Venda de imobilizado (+) \\
Aquisição de imobilizado (-) \\
Aquisição de outras empresas (-) \\
\hline Caixa líquido das atividades de investimento (+/-) \\
\hline Fluxo de Caixa das Atividades de Financiamento: \\
Empréstimos líquidos tomados (+) \\
Pagamento de leasing (-) \\
Emissão de ações (+) \\
\hline Caixa líquido das atividades de financiamento (+/-) \\
\hline (=) Aumento/ diminuição líquido de caixa \\
\hline (+) Caixa- início do período \\
\hline (=) Caixa- final do período \\
\hline
\end{tabular}

Fonte: Marion, (2004 p. 73) Tabela adaptada.

\section{Atividades da DFC}

Além das formas de elaboração, a DFC em sua estrutura compõe três atividades: operacional, investimento e financiamento. Perez Junior (2009, p. 277), ressaltam que "a diferença entre a DFC no método indireto e direto reside apenas na forma de apresentar os recursos derivados das operações".

Conceituando Ribeiro (2002, p. 401),

"É importante salientar que cuidados especiais precisam ser tomados no momento da classificação das transações em seus respectivos grupos de atividades. Ocorre que determinados recebimentos ou pagamentos de caixa podem ter características que se enquadrem tanto o fluxo de caixa operacional, como nas atividades de financiamento ou nas atividades de investimento."

É necessário a verificação do caixa gerado pelas atividades, pois as contas existentes devem ser enquadradas em suas respectivas origens e de forma correta para evitar falhas na apuração dos dados. Completa Cardoso (2007, p. 159) "O modo como os fluxos de caixa é administrado, pode determinar o sucesso ou fracasso de uma empresa." 


\section{Atividades operacionais}

Atividade operacional, são todas as operações geradoras de receita da empresa. Envolvem a produção de bens e serviços geradores de receitas e outros eventos que não são enquadrados como investimento e financiamento. Assaf Neto (2012, p. 354), afirma que "o fluxo de caixa é o resultado de valores gerados pela atividade operacional".

As atividades operacionais da entidade, tendo em visto que a mesma é o principal gerador de recursos financeiros, é o ponto chave da DFC, pois é através dele que será elaborado o fluxo de caixa. O gerenciamento eficaz desse grupo traz benefício diários para o gestor, projetando e acompanhando as receitas em conjunto com as despesas.

Ressaltado que os equivalentes de caixa devem ser agrupados em notas explicativas, conforme Ribeiro (2009, p. 298) afirma “A DFC, quando elaborada, requer que as aplicações financeiras consideradas pela entidade como Equivalentes de Caixa sejam relacionadas em Notas Explicativas".

\section{Atividades de investimento}

Atividade de Investimento, são aquisições ou venda de bens a longo prazo e que não seja enquadro como equivalente de caixa. Exemplo disso, é aquisição de máquina para produção e venda de imobilizado.

Relacionam-se com "o aumento e diminuição dos ativos de longo prazo que a empresa utiliza para produzir bens e serviços" Iudícibus e Martins (2011, p. 442).

Nessa atividade, é possível encontrar os disponíveis da entidade, empréstimo, aquisição ou venda de instrumentos financeiros e patrimoniais, e aquisição e alienação de imobilizado.

\section{Atividades de financiamento}

Atividade de financiamento categoriza os recursos obtidos no passivo circulando e no patrimônio líquido da empresa. Inclui-se nesse grupo, empréstimo, financiamento a curto prazo, saídas para amortização e valores pagos a acionistas.

Relacionam-se com "os empréstimos de credores e investidores a entidade" Schimidt (2007, p. 442). 
São obtidas atividades de financiamento, através de empréstimos a curto e longo prazo, como também por emissões de ações.

\section{Gestão do Fluxo de Caixa}

Diariamente, gestores são desafiados com problemas que exigem soluções em tempo hábil. Para isso, os empreendedores precisam de informações que possam ajudá-los a solucionar tal problema que refletem na sobrevivência da entidade.

Para Marion (1998, p. 92) “A principal função do fluxo de caixa (DFC) é proporcionar ao usuário informações relevantes sobre os ingressos e saídas do caixa". Tal demonstração, em seu aspecto geral fornece ao gestor uma ferramenta de gerenciamento de forma clara e objetiva focando em sua estrutura contas que evidenciam a real situação financeira-econômica da entidade.

O gerenciamento tem por base os relatórios apurados e informados ao gestor, que através dessas informações terá dados para avaliar seu negócio, mensurar de forma eficaz e eficiente os resultados da empresa que estão cada vez mais complexos, pois são determinadas informações que se medem a lucratividade, produtividade e sua rentabilidade.

Diante desse fato, o lucro contábil apurado pela empresa é dividido em: Lucro Contábil Financeiro e Lucro Contábil Econômico. Segundo Marion (2005, p. 159). “A diferença existente entre lucro financeiro e econômico se refere que o primeiro traduz os componentes do caixa - representado pelo fluxo de caixa e o segundo traduz a formalização do lucro - formado pelo balancete gerencial”.

Levando em consideração o lucro contábil financeiro, oriundos das atividades operacionais da entidade ou seu caixa gerado a parte das receitas obtidas com venda de bens, é fundamental para acompanhar o desenvolvimento financeiro, pois, sendo positivo obtém a conclusão que a companhia tem, financeiramente, recursos para amortizar dívidas, fazer investimentos (a curto ou longo prazo), pagar juros e outras ocasiões que necessitam desembolso de dinheiro.

De acordo com a Norma Internacional de Contabilidade - IAS 7, "a principal finalidade da demonstração de fluxo de caixa é a de oferecer informação sobre os recebimentos e os pagamentos de caixa da entidade". Parafraseando Marion (2004, p. 95). “(...) ela objetiva fornecer a compreensão das atividades de investimento e financiamento, de uma entidade". Portanto, a DFC auxilia os credores, fornecedores, e o gestor a avaliar as 
capacidades de gerar caixa, pagar seus fornecedores e se a entidade é capaz de gerar fluxos de forma uniforme e contínua.

Já sendo negativo, é sinal que a entidade não está lucrando o suficiente para pagar suas dívidas adquiridas durante determinada competência, forçando assim os gestores a tomarem medidas urgentes. Tais como corte de custos, mão de obra e serviços que julgam ser desnecessários.

Conforme Cardoso, (2007, p. 159). "O caixa é vital para o bom funcionamento de qualquer empresa". Por sua vez, nenhuma companhia que não gere lucratividade permanece ativa. Gerenciando de forma correta esses recursos, pode se destacar e projetar seu caixa, gerando receitas necessárias para seu sucesso.

Marion (2005, p. 118) afirma que "existem três principais razões de falências ou insucessos de uma empresa, uma delas é a falta de planejamento financeiro ou a ausência total de fluxo de caixa e a previsão de fluxo de caixa (projetar as receitas e as despesas)". Ou seja, para uma entidade ser bem-sucedida financeiramente, não basta apenas ter lucro ao final de cada exercício fiscal, mas sim, pensar como a companhia pode gerar fluxos de caixa futuros para assim garantir sua permanência no mercado.

Para isso, a Demonstração do Fluxo de Caixa vem contribuir de forma positiva para a gestão. Tal demonstração não serve apenas para avaliar quantitativamente o valor em caixa, e sim dar resultados além do Lucro Líquido apurado no final do exercício. As receitas e despesas registradas são lançadas dia a dia, dando suporte ao gestor para avaliar diariamente, semanalmente ou mensalmente todas as movimentações da sua empresa.

"A demonstração do fluxo de caixa é um instrumento analítico valioso tanto para gerentes quanto para investidores e credores”. Marion (1998. p. 554). Com esse pensamento, o autor afirma que a DFC é uma fonte de informações que não apenas os gestores, mas os investidores e credores podem observar a liquidez corrente, e suas vantagens para investimento.

A DFC também pode ser utilizada como base de informação acerca de determinados assuntos que gerem dúvidas para o administrador. "A demonstração do fluxo de caixa pode ser empregada para responder às questões vitais [...]”. Marion (2004, p. 195). Com essa afirmação, concluímos que a DFC vai além das receitas e despesas fixadas. Serve como auxílio para tomada de decisões que envolvam o financeiro.

Iudícibus e Marion (2011, p. 113) afiram que "A DFC propicia ao gerenciamento a elaboração de melhor planejamento, pois, numa economia tipicamente inflacionária, não é aconselhável excesso de caixa". Portanto, ter um fluxo de caixa que possibilite a entidade 
de pagar seus compromissos, evitando a corrosão inflacionária e maior rendimento para a empresa.

Complementando o que foi citado acima, Marion (2002, p. 259) diz que "A comparação do fluxo de caixa projetado, com o real, vem indicar as variações que, quase sempre, demonstram as deficiências nas projeções". Para elaborar um fluxo de caixa futuro, deve se basear em demonstrações passadas, confrontar essas informações que juntas, formam um novo objetivo a ser alcançado através do gerenciamento.

\section{Metodologia}

O presente estudo trata-se de uma pesquisa bibliográfica, de cunho descritivo e exploratório, que segundo Gil $(2002$, p. 17) a pesquisa é bibliográfica quando "Se realiza a partir do registo disponível, decorrente de pesquisas anteriores, em documentos impressos, como livros, artigos, teses etc".

O meio de investigação utilizado nesse documento foi de cunho bibliográfico para aperfeiçoar o assunto e consequentemente explicar a utilização da DFC para as entidades, e sua colaboração para o gerenciamento empresarial. Por tanto, utilizou-se de abras já publicadas, bem como artigos específicos da área.

A abordagem se deu pelo método qualitativo, que teve como foco sancionar os objetivos da pesquisa. Essa abordagem teve como análise o uso da DFC como auxílio no âmbito empresarial das empresas, levando ao seu sucesso financeiro e consequentemente no mercado empresário. Para Godoy (1995, p. 21) "Com pesquisa qualitativa queremos dizer qualquer tipo de pesquisa que produza resultados não alcançados através de procedimentos estratégicos ou de outros meios de quantificação".

Por fim, a pesquisa é exploratória, pois "busca apenas levantar informações sobre um determinado objeto, delimitando assim um campo de trabalho, mapeado as condições de manifestação desse objeto". (SILVA, 2008).

As informações foram obtidas e analisadas, expondo de forma a esclarecer a importância da demonstração e sua relevância para a entidade no gerenciamento, como também os métodos de elaboração da DFC. 


\section{Considerações Finais}

Nos dias atuais, as entidades devem inovar cada vez mais para permanecer no mercado, devendo constantemente mudar a forma de obter informações. Nesse sentido, a informação é crucial no crescimento da empresa. O empresário, deve buscar de forma clara essas informações para alcançar seu objetivo, a lucratividade.

As entidades devem buscar informações que facilitem no desenvolvimento da companhia, gerando dados significativos para o âmbito empresarial.

Considera-se que a DFC é um relatório que evidência as entradas e saídas de caixa e seus equivalentes, sendo elaborado por dois métodos. O método indireto, parte do lucro líquido da empresa, sendo ajustado as contas de depreciação e amortização. Método direto é elaborado pelos pagamentos e recebimentos decorrentes das atividades operacionais da empresa, devendo apresentar os componentes do fluxo por seus valores brutos.

A DFC é estruturada por mais três tipos de atividades, são elas operacional, investimento e financiamento. A atividade operacional representa as atividades de caixa do objetivo principal da empresa, atividade de investimento são representados por ativos permanentes e temporários da empresa, como por exemplo compra e venda de imobilizado. Já as atividades de financiamento, inclui os recursos de terceiros e os recursos próprios recebidos.

Portanto, a DFC é uma ferramenta indispensável no âmbito empresarial, pois tem importante poder informacional e gerencial, motivo pelo qual, independente do porte da empresa, a sua elaboração é fundamental para o entendimento das operações das organizações.

Sugere-se que sejam realizados estudos futuros utilizando-se os indicadores financeiros da DFC para que se possa ter uma melhor visão acerca do empreendimento.

\section{Referências}

ASSAF NETO, Alexandre. Gestão do Fluxo de Caixa. Perspectivas Estratégica e Tática. 10. ed. São Paulo: Atlas, 2012

AZEVEDO, Marcelo Cardoso de. Estrutura e análise das demonstrações financeiras. 2. ed. - Campinas, SP: Alínea, 2013. 
BRAGA, Hugo Rocha: Estrutura, análise e interpretação - 7. ed. São Paulo: Atlas, 2012.

BRASIL. Lei 11.638/2007. Disponível em: <http://www.planalto.gov.br/ccivil_03/_Ato2007-2010/2007/Lei/L11638.htm>. Acessado em 12 de Set. 2018.

CARDOSO, Ricardo Lopes: Contabilidade gerencial: mensuração, monitoramento e incentivos - São Paulo: Atlas, 2007.

FRANCO, Hilário: Contabilidade geral - 23. Ed. - São Paulo: Atlas, 1996.

GIL, Antônio Carlos. Como elaborar projeto de pesquisa. 4. ed. São Paulo: Atlas, 2002.

GODOY, A. S (1995). Introdução a pesquisa qualitativa e suas possibilidades. Revesta de Administração de empresas. P. 58. Disponível em: < https://rae.fgv.br>. Acessado em 30 de out. 2018

ILDICIBUS, Sergio de: Teoria da contabilidade - 10. ed. - São Paulo: Atlas, 2010.

, Sergio de; MARION, José Carlos: Curso de contabilidade para não contadores - 7. ed. - São Paulo: Atlas, 2011.

MARION, Jose Carlos: Análise das demonstrações contábeis: Contabilidade empresarial. 2. Ed. - São Paulo: Atlas, 2002.

, Contabilidade empresarial - 11. ed. - São Paulo: Atlas, 2005

Contabilidade básica - 6. ed. - São Paulo: Atlas, 1998.

PEREZ JUNIOR, José Hernandez: Elaboração e análise das demonstrações contábeis 4. Ed. - São Paulo: Atlas, 2009.

RESOLUÇÃO, CPC n ${ }^{\circ} 03$ (R2) - Demonstração do fluxo de caixa. Disponível em: http://static.cpc.aatb.com.br/Documentos/183_CPC_03_R2_rev\%2013.pdf. Acessado em 26 de Outubro de 2018.

RESOLUÇÃO, IAS 7 Demonstração do fluxo de caixa. Disponível em <https://www.bcb.gov.br/nor/convergencia/IAS_07_Demonstracao_dos_Fluxos_de_Caixa. pdf $>$. Acessado em 30 de outubro de 2018.

RESOLUÇÃO, NBC TG 03 (R3) - Demonstração do fluxo de caixa. Disponível em: < http://www2.cfc.org.br/sisweb/sre/detalhes_sre.aspx?Codigo=2016/NBCTG03(R3)\&arquiv $\mathrm{o}=$ NBCTG03(R3).doc $>$ Acessado em 25 de Outubro de 2018.

RIBEIRO, Osni Moura: Contabilidade geral fácil - 5. Ed. Ampl. e atual. - São Paulo: Saraiva, 2009.

, Contabilidade básica fácil - 23. ed. rev. e atual. - São Paulo: Saraiva, 2002 
SCHIMIDT, Paulo: Contabilidade intermediária: atualizada pela Lei nº11.941/09 e pelas normas do CPC - 2. ed. - São Paulo: Atlas, 2011.

SILVA, Antônio Carlos Ribeiro de. Metodologia da pesquisa aplicada à contabilidade: orientações de estudo, projetos, relatórios e monografias, dissertações, testes - São Paulo: Atlas. 2003.

\section{Como citar este artigo (Formato ABNT):}

SOUSA, Jair Bruno Pereira de; DIAS, Tays Cardoso. A Gestão do Fluxo de Caixa no Âmbito Empresarial. Id on Line Rev.Mult. Psic., 2019, vol.13, n.43, p. 873-887. ISSN: 1981-1179.

Recebido: 25/11/2018;

Aceito: $27 / 11 / 2018$ 